\title{
NOTE ON A MERCURY SPARK GAP FOR INSTANTA- NEOUS PHOTOGRAPHY
}

\author{
By L. F. Curtiss
}

ABSTRACT

The improved form of high voltage mercury spark gap for instantaneous photography here described eliminates dangers from mercury poisoning. By including a bulb of cooler mercury vapor, through which the discharge does not pass, the shock caused by the sudden rise of pressure in the inclosing tube is partially absorbed. This greatly prolongs the life of the inclosing tube. It has been found that pyrex glass is quite suitable as a container.

The type of mercury spark gap used by C. T. R. Wilson ${ }^{1}$ for photographing $\alpha$-ray and $\beta$-ray tracks is a convenient source of illumination of great intensity for instantaneous photography. In the open form, as described by Wilson, it is not suitable for continuous use, particularly in a poorly ventilated room, since there is great danger of mercury vapor poisoning. Another annoying circumstance attendant on its use is the frequent shattering of the luminous portion of the tube containing the spark gap. This note gives a brief description of a design of the spark gap which eliminates both of these difficulties.

The spark gap in its usual form consists of a pyrex or quartz $U$-shaped open tube filled with mercury. The horizontal portion is of small cross section. It is operated by heating the mercury in the horizontal part until the hot mercury vapor separates the mercury into two columns. A condenser charged to 20,000 to 50,000 volts is then discharged through the hot mercury vapor, which is, of course, at a pressure slightly higher than atmospheric. The shattering of the tubes is a result of the sudden rise in pressure caused by the discharge, repeated shocks finally splitting the tube. The writer has tried both quartz and pyrex as containers, and as regards durability there is little to choose between them. Since the extreme ultraviolet is not utilized in ordinary photography and pyrex is much cheaper, it has been used in the spark gap to be described. Pyrex offers the further advantage that tungsten leads can be sealed into it easily to prevent the escape of the hot mercury vapor.

Figure 1 is a diagram of the spark gap filled with mercury before final sealing. It consists of a horizontal capillary $C$, of 0.5 to $3.0 \mathrm{~mm}$ diameter, terminating at one end in a bulb $B$, and at the other in the reservoir $R$, which carries a short, vertical stem. The spark gap is prepared by expelling all air by repeated boiling. The wire $W_{2}$ is then inserted, extending into the capillary, and sealed in, as shown 
in Figure 2. To operate, the mercury in $B$ and $C$ is heated by a coil $H$, of resistance wire wound throughout the horizontal length of the tube until the mercury has taken the position shown in Figure 2. The current through the coil is adjusted to maintain this position. The capillary and bulb $B$ are now filled with hot mercury vapor which is held against a cushion of compressed air in the tube above

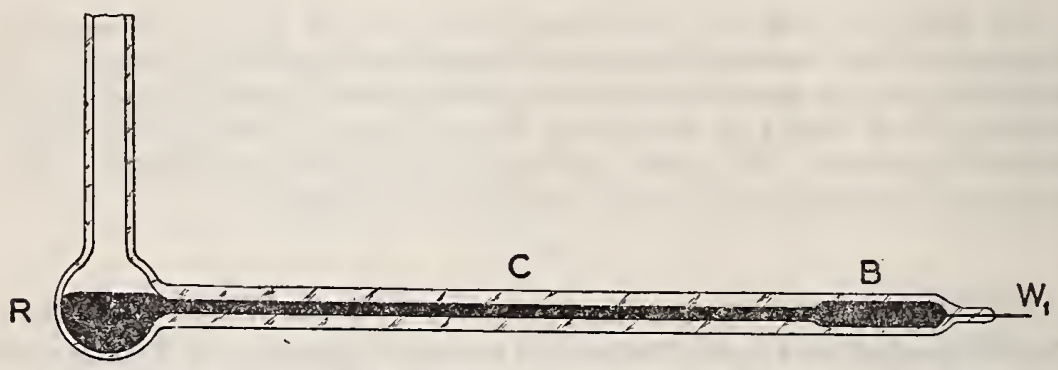

FIGURE 1.-Showing spark gap filled with mercury before sealing

the mercury reservoir $R$. When the condenser is discharged between the wires $W_{1}$ and $W_{2}$ the mercury vapor in $C$ is heated suddenly while that in $B$ remains at the same temperature as before, since the discharge does not pass through it. This cooler volume of mercury vapor serves to reduce the shock of the sudden rise in pressure in the capillary during the instant of flashing of the spark. It has been

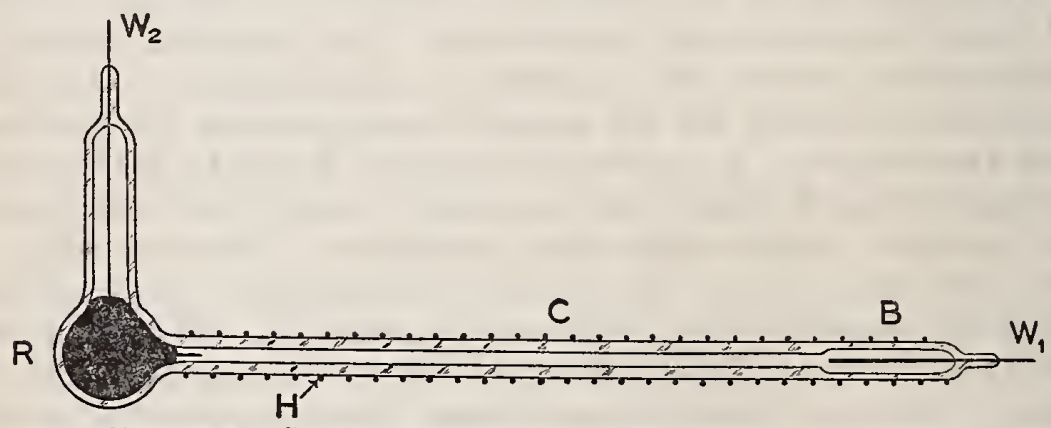

FIGURE 2.-Spark gap after sealing, heated ready for operation

found that under normal conditions this arrangement practically eliminates splitting of the capillary.

It should be noted in Figure 2 that the wire $W_{2}$ projects through the mercury into the capillary so that the discharge passes from one tungsten wire to the other. This arrangement is important for pyrex tubes. If the discharge is allowed to pass from the mercury in the reservoir to the wire $W_{1}$, a slight oscillation in the position of the mercury in the capillary is produced which repeatedly chills the pyrex until it cracks at the point where the reservoir is sealed to the capillary. 
When it is desirable to use a spark gap of this kind as an instantaneous source of ultra-violet this design may also be made in quartz by using graded seals to pyrex and sealing the tungsten through the pyrex as before.

It may also be well to mention that if air is present with the hot mercury vapor in the luminous portion of the arc the glass or quartz soon discolors badly, cutting down the intensity considerably. This trouble may be avoided by carefully boiling the mercury when filling the tube so that all air is expelled from the capillary.

Washington, February 13, 1929. 